\title{
Donor Recipient Chimeric Cells Induce Chimerism and Extend Survival of Vascularized Composite Allografts
}

\author{
Joanna Cwykiel ${ }^{1,2} \cdot$ Arkadiusz Jundzill $^{2,3,4}$ - Aleksandra Klimczak ${ }^{2,5} \cdot$ Maria Madajka-Niemeyer $^{2}$. \\ Maria Siemionow ${ }^{1,2,6}$ (D)
}

Received: 13 February 2021 / Accepted: 8 April 2021 / Published online: 10 May 2021

(c) The Author(s) 2021

\begin{abstract}
This study evaluated the efficacy of donor recipient chimeric cell (DRCC) therapy created by fusion of donor and recipient derived bone marrow cells (BMC) in chimerism and tolerance induction in a rat vascularized composite allograft (VCA) model. Twenty-four VCA (groin flaps) from MHC-mismatched ACI $\left(\mathrm{RT}^{1}{ }^{\mathrm{a}}\right)$ donors were transplanted to Lewis $\left(\mathrm{RT}^{1}\right)$ recipients. Rats were randomly divided into ( $n=6$ /group): Group 1-untreated controls, Groups 2-7-day immunosuppression controls, Group 3-DRCC, and Group 4-DRCC with 7-day anti- $\alpha \beta$ TCR monoclonal antibody and cyclosporine A protocol. DRCC created by polyethylene glycol-mediated fusion of ACI and Lewis BMC were cultured and transplanted $\left(2-4 \times 10^{6}\right)$ to VCA recipients via intraosseous delivery route. Flow cytometry assessed peripheral blood chimerism while fluorescent microscopy and PCR tested the presence of DRCC in the recipient's blood, bone marrow (BM), and lymphoid organs at the study endpoint (VCA rejection). No complications were observed after DRCC intraosseous delivery. Group 4 presented the longest average VCA survival ( $79.3 \pm 30.9$ days) followed by Group 2 (53.3 \pm 13.6 days), Group 3 (18 \pm 7.5 days), and Group 1 ( $8.5 \pm 1$ days). The highest chimerism level was detected in Group $4(57.9 \pm 6.2 \%)$ at day 7 post-transplant. The chimerism declined at day 21 post-transplant and remained at $10 \%$ level during the entire follow-up period. Single dose of DRCC therapy induced long-term multilineage chimerism and extended VCA survival. DRCC introduces a novel concept of customized donor-recipient cell-based therapy supporting solid organ and VCA transplants.
\end{abstract}

Keywords Donor recipient chimeric cells · Vascularized composite allotransplantation · Cell fusion · Groin flap

Maria Siemionow

siemiom@uic.edu; siemiom@hotmail.com

1 Department of Orthopaedics, University of Illinois At Chicago, Molecular Biology Research Building, $900 \mathrm{~S}$. Ashland Ave. Room\# 3356, Chicago, IL 60607, USA

2 Department of Plastic Surgery, Cleveland Clinic, Cleveland, $\mathrm{OH}$, USA

3 Chair of Urology, Department of Regenerative Medicine, Nicolaus Copernicus University in Torun, Ludwik Rydygier Medical College in Bydgoszcz, Bydgoszcz, Poland

4 Department of Plastic, Reconstructive and Aesthetic Surgery, Collegium Medicum in Bydgoszcz, Nicolaus Copernicus University in Toruń, Bydgoszcz, Poland

$5 \quad$ Hirszfeld Institute of Immunology and Experimental Therapy, Polish Academy of Sciences, Wroclaw, Poland

6 Department of Surgery, Poznan University of Medical Sciences, Poznan, Poland

\section{Introduction}

The continued effort to introduce new solutions into the field of transplantation is driven by the need to limit the use of anti-rejection protocols which, although necessary, are associated with severe co-morbidities and significant shortening of transplant recipient's lifespan.

Cell-based therapies were proposed as a promising supportive treatment due to observed direct and indirect involvement of cells of hematopoietic and mesenchymal origin in the alteration of the local and systemic immune response of the transplant recipients (Siemionow et al. 2012). Research effort focused on bone marrow transplantation (BMT) and bone marrow cell (BMC) based therapies provided encouraging results supporting the hypothesis of the importance of longterm chimerism in transplant tolerance induction (Leventhal and Ildstad 2018; Mathes et al. 2014; Scandling et al. 2008; Siemionow et al. 2002a, b, 2003, 2008). The experimental in vitro studies of BMC and clinical BMT studies reported 
the occurrence of cells presenting phenotype and/or genotype make-up specific for both the transplant donor and recipient and suggested contribution of the donor/recipient cells to the processes such as regeneration and immune response (Alvarez-Dolado et al. 2003; Camargo et al. 2004; Johansson et al. 2008; LaBarge and Blau 2002; Lluis and Cosma 2010; Nygren et al. 2004; Powell et al. 2011; Rizvi et al. 2006; Sanges et al. 2013; Vassilopoulos et al. 2003; Wang et al. 2003; Weimann et al. 2003; Willenbring et al. 2004). These cells are a product of either cell fusion, an ubiquitous process of asexual merging of two or more parental cells (Dittmar and Zanker 2015; Zito et al. 2016), or trogocytosis, a process of transfer of cell membrane fragments with associated proteins between cells (Ahmed et al. 2008). Our group, following the detection of donor/recipient cells in a rat BMT recipient, developed a protocol to create donor-recipient chimeric cells (DRCC) in vivo and tested the effect of DRCC's in a fully MHC-mismatched rat vascularized composite allotransplantation (VCA; hemiface) model (Hivelin et al. 2016). Application of DRCC as a supportive therapy under a short-term immunosuppression (IS) protocol of anti- $\alpha \beta$ TCR monoclonal antibody and cyclosporine A (anti- $\alpha \beta T C R / C s A)$ was associated with prolonged VCA survival (Hivelin et al. 2016). The improvement of VCA survival time could have been caused by the combination of multi-lineage chimerism induction and/or immunomodulatory properties of in vivo created DRCC (Hivelin et al. 2016).

Based on these encouraging results, we have created a novel clinically feasible DRCC therapy using an ex vivo polyethylene glycol (PEG)-mediated fusion of BMC isolated from transplant donor and recipient (Cwykiel et al. 2021). Our study confirmed the chimeric phenotype and genotype make-up of DRCC using flow cytometry, confocal microscopy, and PCR. In addition, we showed that the applied ex vivo cell fusion procedure was not genotoxic and did not change the expression of the hematopoietic markers, proliferation rate or differentiation potential of DRCC compared to BMC controls. In vitro evaluation indicated pro-tolerogenic profile of DRCC presented by decreased immunogenicity and secretion of pro-tolerogenic IL-10 and TGF $\beta 1$ cytokines (Cwykiel et al. 2021).

This study focused on the assessment of immunomodulatory effect of DRCC therapy in vivo to support tolerance induction in a rat VCA (groin flap) model containing highly immunogenic skin component. In addition, we evaluated the potential of DRCC for chimerism induction and DRCC's migration pattern in vivo at the experimental endpoint.

\section{Materials and Methods}

\section{Experimental Design}

Cleveland Clinic's Institutional Animal Care and Use Committee (IACUC, Cleveland, $\mathrm{OH}$ ), accredited by the
American Association for the Accreditation of Laboratory Animal Care (AAALAC, \#2012-0841), approved this study. All animals received humane care in compliance with the "Principles of Laboratory Animal Care" formulated by the National Society for Medical Research and the "Guide for the Care and Use of Laboratory Animal Resources" (2011) published by the US National Institutes of Health.

A total of 24 vascularized skin allografts (VSA; groin flaps) have been transplanted between 7 and 10 weeks old male ACI (August Copenhagen Irish, $\mathrm{RT} 1^{\mathrm{a}}$ ) donors and Lewis (RT $1^{1}$ ) recipients (weight $250-300 \mathrm{~g}$; Envigo, USA). The VCA Lewis recipients were randomly divided into four groups ( $n=6$ /group): Group $1-$ did not receive any treatment; Group 2 -was supported by 7 -day anti- $\alpha \beta T C R / C s A$ immunosuppression (IS) protocol; Group 3-was supported with DRCC $\left(2-4 \times 10^{6}\right.$ cells $)$ therapy delivered via intraosseous injection to recipient's femur; and Group 4-was supported with intraosseous delivery of DRCC $\left(2-4 \times 10^{6}\right.$ cells) therapy and 7 -day anti- $\alpha \beta T C R / C s A$ IS protocol. The IS protocol included intraperitoneal injection of anti- $\alpha \beta \mathrm{TCR}$ monoclonal antibody ( $250 \mu \mathrm{g} /$ day, clone R73; BD Pharmingen, USA) and subcutaneous injection of CsA (16 mg/kg/ day; Bedford Laboratories, USA). The experimental design is presented in detail in Fig. 1.

\section{Creation of DRCC Therapy via Ex Vivo Cell Fusion}

Forty-eight male 7-8 weeks old ACI (RT1 $\left.{ }^{\mathrm{a}}\right)$ and 48 Lewis $\left(\mathrm{RT}^{1}{ }^{1}\right)$ rats served as donors for the creation of DRCC therapy (Envigo, USA). BMC were isolated in a sterile manner, as previously described (Cwykiel et al. 2021; Hivelin et al. 2016; Siemionow et al. 2016), from femurs and tibias using flashing technique. Harvested cells were filtered using $40 \mu \mathrm{m}$ strainer, purified by Histopaque 1084 (Millipore-Sigma, USA) and counted with $0.4 \%$ Trypan Blue (Thermo Fisher Scientific, USA). Next, BMC from each donor strain were stained either with PKH26 (ACI) or PKH67 (Lewis) fluorescent dyes (Millipore-Sigma, USA) for $3 \mathrm{~min}$ as previously reported (Cwykiel et al. 2021; Siemionow et al. 2016, 2018a; b). Following staining, PKH26-ACI BMC and PKH67-Lewis BMC were mixed and re-suspended in RPMI 1640 medium without fetal bovine serum (FBS). Fusion was performed as previously reported (Cwykiel et al. 2021; Siemionow et al. 2018a, b) using 50\% w/v polyethylene glycol 4000 (EMD, USA) and 16\% dimethyl sulfoxide (DMSO). PKH26/PKH67 labeled DRCC were selected using Special Order BD FACS Aria II. Purity and viability of DRCC $\left(1 \times 10^{5}\right.$ cells, $\left.n=3\right)$ were assessed using LSRFortessa cytometer (BD, Franklin Lakes, NJ, USA). The chimeric state of DRCC was confirmed as previously reported by confocal microscopy and flow cytometry (Cwykiel et al. 2021; Siemionow et al. 2018a, b). Next, sorted DRCC were cultured for 5 days in "enriched" StemSpan ${ }^{\circledR}$ SFEM 


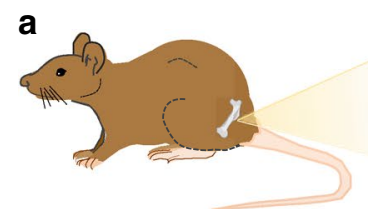

ACI BMC Donor

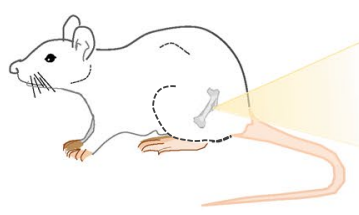

Lewis BMC Donor

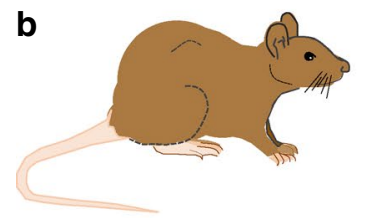

ACI VCA Donor

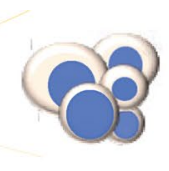

Isolated ACI BMC
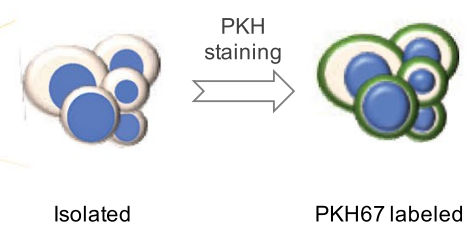

Lewis BMC

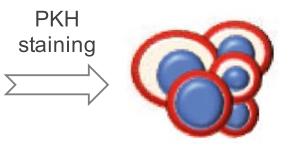

PKH26 labeled ACI BMC

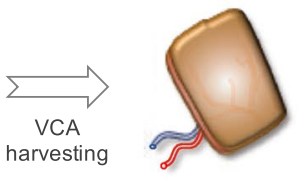

Harvested ACI VCA

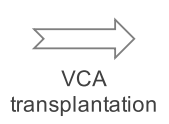

Lewis BMC

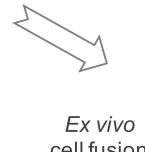

cell fusion
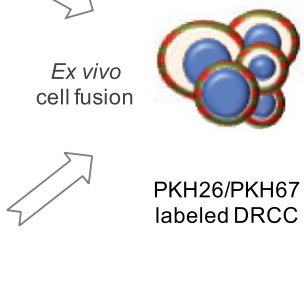

PKH26/PKH67 labeled DRCC

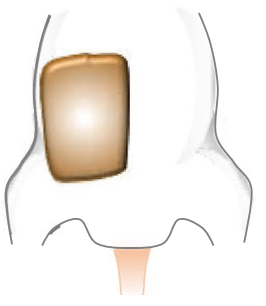

ACI VCA transplanted to Lewis recipient

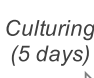

(5 days)
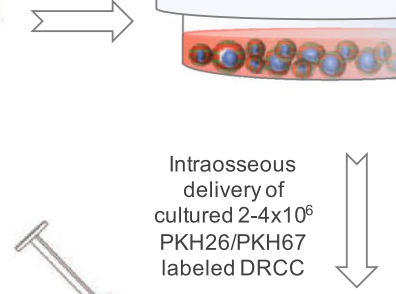

Culturing of $\mathrm{PKH} 26 / \mathrm{PKH} 67$ labeled DRCC

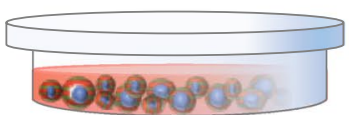

Intraosseous

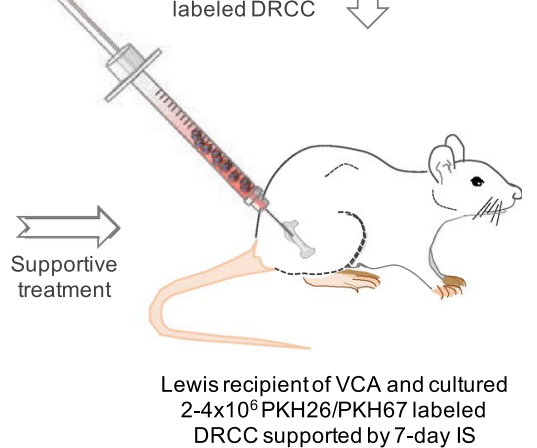

Fig. 1 Diagram of the experimental study design. a Creation of donor recipient chimeric cells (DRCC) therapy via ex vivo cell fusion. From left: bone marrow cells (BMC) were isolated from ACI $\left(\mathrm{RT}^{\mathrm{a}}\right)$ and Lewis $\left(\mathrm{RT}^{1}{ }^{1}\right)$ donor rats and labeled with PKH26 (ACI BMC) or PKH67 (Lewis BMC). PKH labeled BMC of ACI and Lewis origin were mixed, and PEG-mediated fusion procedure was performed. Double PKH26/PKH67 labeled DRCC were sorted and cultured in "enriched" StemSpan ${ }^{\circledR}$ SFEM medium. Following 5-day culture,

medium containing 10\% FBS (Thermo Fisher Scientific), $1 \times$ antibiotics/antimycotic solution (Millipore-Sigma) and cytokine mix (Zhang and Lodish 2005) containing: recombinant human acidic fibroblast growth factor $(10 \mathrm{ng} / \mathrm{mL})$, recombinant mouse stem cell factor $(10 \mathrm{ng} / \mathrm{mL})$, recombinant mouse thrombopoietin $(20 \mathrm{ng} / \mathrm{mL})$, recombinant mouse insulin growth factor-II ( $20 \mathrm{ng} / \mathrm{mL}$; R\&D Systems, USA), and heparin $(10 \mu \mathrm{g} / \mathrm{mL}$; Millipore-Sigma, USA).

\section{Vascularized Composite Allograft (Groin Flap) Transplantation}

The technical details of the groin flap transplantation procedure were previously published (Demir et al. 2005; Siemionow et al. 2016). Briefly, the right groin and leg area of donor and recipient rats anesthetized with subcutaneous injection of ketamine $(30 \mathrm{mg} / \mathrm{kg})$, acepromazine $(6 \mathrm{mg} / \mathrm{kg})$, and xylazine ( $1 \mathrm{mg} / \mathrm{kg})$, were shaved, sterilized, and draped in a sterile fashion. Surgical marker was used to outline the area of allograft including the xiphoid and pubis midline, the inguinal ligament inferiorly, costal arch superiorly, and
DRCC were applied as a supportive therapy for vascularized composite allograft (VCA) recipients. b VCA (groin flap) transplantation and application of DRCC therapy. From left: VCA was harvested from $\mathrm{ACI}\left(\mathrm{RT} 1^{\mathrm{a}}\right)$ donor rat and transplanted to the groin region of fully MHC-mismatched Lewis $\left(\mathrm{RT}^{1}{ }^{1}\right)$ recipient. Following transplantation, VCA recipients received intraosseous injection of cultured $2-4 \times 10^{6}$ DRCC and a 7-day immunosuppression (IS) protocol of anti- $\alpha \beta T C R$ monoclonal antibody and CsA

axillary line laterally. Transplantation procedures were performed under $40 \times$ operating microscope magnification.

\section{VCA Harvest}

The $3 \times 3 \mathrm{~cm}$ groin flap was raised exposing the pedicle, and a retractor was placed in the caudal aspect of the VCA. The lateral femoral circumflex artery and vein, and any additional femoral branches to adjacent muscles were ligated using 10-0 nylon monofilament suture. A pair of straight microsurgical scissors was used to cut the isolated femoral artery and vein and trim a cuff of adventitia close to the vascular section. Heparinized normal saline $(10 \mathrm{IU} / \mathrm{ml})$ was used to flush the lumens of femoral vessels while Addison's forceps were applied to transfer the VCA. The groin flap was kept in moist gauze pre-transplantation.

\section{VCA Recipient Preparation}

The same method of VCA dissection as for ACI donor was also applied for the Lewis recipient. The transected femoral vessels were flushed with heparinized normal saline (10 IU/ 
$\mathrm{ml})$ and the recipient's graft $(3 \times 3 \mathrm{~cm})$ was removed creating the defect required for transplantation of the ACI donor VCA.

\section{Transplantation Procedure}

Following VCA transfer, end-to-end anastomosis between the ACI donor and Lewis recipient femoral arteries and veins were performed under operating microscope (magnification $\times 40$ ) with $10-0$ nylon monofilament sutures using standard microsurgical techniques. Warm ischemia time upon the grafts' revascularization was limited to approximately $55 \mathrm{~min}$ in each case. The patency of anastomoses was confirmed, and the vessels were inspected for signs of hemorrhage, thrombosis or excessive traction. After restoration of perfusion subcutaneous interrupted sutures (5-0 Vicryl, Ethicon) were used to close the skin (Demir et al. 2005). VCA recipients in Groups 2 and 4 received subcutaneous injections of CsA $(16 \mathrm{mg} / \mathrm{kg} /$ day $)$ and intraperitoneal injection of anti- $\alpha \beta$ T cell receptor (TCR) monoclonal antibody $(250 \mu \mathrm{g} /$ day $)$ for 7 days with the first injections at the day of VCA transplantation. Buprenorphine $(0.075 \mathrm{mg} / \mathrm{kg})$ was administered twice daily for 3 days after the surgery as analgesic. Following the completion of VCA transplantation, the cultured DRCC therapy has been delivered to the VCA recipient's femoral bone as previously reported (Hivelin et al. 2016; Klimczak et al. 2007; Siemionow et al. 2005a).

\section{Gross Examination of Transplanted VCA}

During the post-transplant period, the animals were evaluated daily for the presence of any signs of pain or stress, while the VCA were monitored for any clinical signs of rejection, such as erythema, hair loss, edema, epidermolysis, ulceration, graft shrinkage, and mummification. The necrosis of $80 \%$ of the flap was considered as a rejection and experimental endpoint (Demir et al. 2005; Hivelin et al. 2016; Lei et al. 2019; Siemionow et al. 2016).

\section{Evaluation of Peripheral Blood Chimerism in the VCA Transplant Recipients by Flow Cytometry}

Blood samples were harvested from VCA recipients at days 7, 21, 35, 63, and 100 post-transplantation. Red blood cells were removed form blood samples using $0.83 \% \mathrm{NH}_{4} \mathrm{CI} /$ Tris (Sigma-Aldrich, USA) solution (Klimczak et al. 2007), and isolated cells were washed twice with Dulbecco's phosphate buffered saline (D-PBS). Further, cells were resuspended in a cell staining buffer solution containing $1 \%$ BSA and $0.05 \%$ sodium azide in $1 \times \mathrm{PBS}$ and incubated with fluorescein isothiocyanate (FITC)- and phycoerythrin (PE)-labeled monoclonal antibodies or isotype controls for $30 \mathrm{~min}$ on ice. The following monoclonal antibodies were used for staining:
FITC-conjugated: mouse anti-rat CD3 (BD554832), rat antirat $\mathrm{RT}^{\mathrm{ab}}$, (BD550981), mouse anti-rat CD4 (BD554837), and mouse anti-rat $\alpha \beta$-TCR (BD554913), as well as PE-conjugated PE mouse anti-rat CD45RA, (BD554884), mouse anti-rat CD4 (BD554838), mouse anti-rat CD8 (BD554857), mouse anti-rat $\gamma \delta$-TCR (BD551802), and mouse anti-rat CD25 (BD554866). Next, cells were washed twice with cell staining buffer and fixed with $1 \%$ neutral buffered formalin in $1 \times$ PBS overnight. Labeled cells were analyzed on a FACSScan (Coulter, EPICS Elite-ESP) and BD LSRFortessa ${ }^{\mathrm{TM}}$ (BD Biosciences, USA) flow cytometers. Ten thousand cells were acquired for each tested sample.

\section{Detection of DRCC Migration In Vivo by Polymerase Chain Reaction and Confocal Microscopy}

At the experimental endpoint, the VCA recipients were humanly euthanized by buprenorphine overdose, and blood, bone marrow (BM) from injected bone and lymphoid tissues (thymus, spleen, and lymph node) samples were harvested.

Microscopy analysis: Tissue samples were placed in a Tissue-Tek Cryomold and covered in Tissue-Tek ${ }^{\circledR}$ O.C.T. (Sakura Finetek USA Inc., USA) and flash frozen. Samples were sectioned using Microm HM 525 cryostat (Thermo Fisher Scientific, USA). Sections $(5 \mu \mathrm{m})$ were fixed in $4 \%$ paraformaldehyde for $10 \mathrm{~min}$ and then rinsed in Tris buffered saline (Dako, Germany). Slides mounted in Vectashield mounting medium with DAPI (Vector Laboratories, USA) were analyzed using fluorescence microscopes (Leica, Germany). The presence of DRCC within the tissue was assessed based on double PKH26/PKH67 labeling. For analysis of peripheral blood and BM, cells were isolated as described above. Next, blood $(100 \mu \mathrm{l})$ and BM $(2 \mathrm{ml})$ were lysed using $20 \mathrm{ml}$ of ACK buffer (Thermo Fisher Scientific, USA) for $4 \mathrm{~min}$ at room temperature, centrifuged at $300 \times \mathrm{g}$ for $5 \mathrm{~min}$ and washed with $1 \times$ D-PBS two times. Next, the sample was fixed with $4 \%$ paraformaldehyde for $15 \mathrm{~min}$ and washed again with $1 \times$ D-PBS. Cells were suspended in $50 \mu \mathrm{l}$ of $1 \times \mathrm{D}$-PBS and $10 \mu \mathrm{l}$ was applied on a base slide (Fisherbrand ${ }^{\mathrm{TM}}$ Superfrost ${ }^{\mathrm{TM}}$ Plus Microscope Slides, USA) together with $1 \mu \mathrm{l}$ of DAPI solution $(300 \mathrm{nM}$; Thermo Fisher Scientific) and cover with coverglass (Thermo Fisher Scientific, USA). Slides were assessed within $30 \mathrm{~min}$ after preparation using Leica TCS-SP upright confocal microscope.

Polymerase chain reaction (PCR) analysis: The samples of peripheral blood $(100 \mu \mathrm{l}), \mathrm{BM}\left(1 \times 10^{6}\right.$ cells $)$ as well as thymus, lymph nodes, and spleen were harvested at the experimental endpoint (VCA rejection). DNA was isolated using DNeasy Blood \& Tissue Kit (QIAGEN, Germany) according to the manufacturer's instructions. PCR was performed as previously described (Siemionow et al. 2016). 


\section{Statistical Analysis}

All results are presented as mean \pm standard deviation (SD). A log-rank test was used to assess the overall difference in freedom of rejection among experimental groups. For chimerism evaluation: the normal distribution of the sample was confirmed using Anderson-Darling test. The GLM analysis assessed the mean differences among experimental groups and was followed by post hoc Bonferroni test compared the trend over time were assessed by examining the interaction between group and time. The comparison of groups' means was performed for four groups with a Bonferroni-adjusted significance level for multiple comparisons. Minitab 2017 software (OriginLab Corp. USA) was used to perform statistical analysis. $* p<0.05,{ }^{* *} p<0.01$, $* * * p<0.001$.

\section{Results}

\section{Application of DRCC Supportive Therapy is Associated with Significantly Prolonged Survival of Fully MHC-Mismatched VCA}

No complications following surgical procedure or DRCC injection were observed. No graft-vs.-host disease symptoms occurred following DRCC delivery. The transplanted VCA (groin flaps) were examined daily for signs of rejection (Fig. 2). The acute rejection occurred in all experimental groups. The average VCA survival time ranged from 8-125 days post-transplant (PT) and showed the following average survival times: Group 1 (untreated VCA recipient, control group) $8.5 \pm 1$ days PT, Group 2 (VCA recipients under 7-day anti- $\alpha \beta$ TCR/CsA IS protocol) $53.3 \pm 13.6$ days PT $(p<0.001$ vs. Group 1), Group 3 (VCA recipients supported with DRCC therapy) $18 \pm 7.5$ days PT ( $p=0.01$ vs. Group 1 and $p<0.001$ vs. Group 2), and Group 4 (VCA recipients supported with DRCC therapy and 7-day anti$\alpha \beta$ TCR/CsA IS protocol) $79.3 \pm 30.9$ days PT. The VCA survivals in Group 4 were significantly prolonged in comparison to untreated VCA recipient controls (Group 1, $p<0.001)$, VCA recipients group supported with 7-day IS protocol (Group 2, $p<0.05$ ) and VCA recipients supported with DRCC therapy (Group 3, $p<0.001$ ). The Kaplan-Meier VCA survival curve is presented in Fig. 3.

\section{Application of Short-Term IS Protocol Facilitates the DRCC Engraftment and Development of Peripheral Blood Chimerism}

The average percentage of T-cell population expressing CD3 in untreated (Group 1) and DRCC supported VCA recipients (Group 3) was $70.6 \pm 5.4 \%$ and $74.4 \pm 9.6 \%$, respectively. Groups 2 and 4 which received the 7-day IS protocol showed a significant depletion of $\mathrm{CD} 3$ population (Group 2-4.2 $\pm 0.4 \% * * *$ and Group 4-5.1 $\pm 3.5 \% * * *$, $* * * p<0.001$ vs. Groups 1 and 3; Fig. 4a).

The decreased percentage of CD3-positive cells was maintained in Groups 2 and 4 on day 21 and 35 PT (day $21-2.7 \pm 1.7 \% * * *, 10.4 \pm 2.8 \% * * *$, day $35-7.9 \pm 4.6 \% * * *, 23.9 \pm 10.8 \% * * *$, respectively; $* * * p<0.001$ vs. Group 3). Further, the CD3 population recovery was detected at day $63 \mathrm{PT}$ (Group $2-28.3 \pm 5.8 \%$ * and Group $4-53.2 \pm 16.5 \%,{ }^{*} p<0.05$ vs. Group 4$)$. At day 100 PT the population of CD3-positive cells in Group 4 reached $64.5 \pm 2.1 \%$.

The application of IS protocol also decreased the average percentage of CD4 positive cells in Groups 2 and 4 between days 7 and 35 PT (day 7-47.1 $\pm 5.1 \%^{* *}$ and $48.5 \pm 7.3 \% * *$, day $21-32.2 \pm 8.7 \% * *$ and $37.9 \pm 6.8 \% * *$,
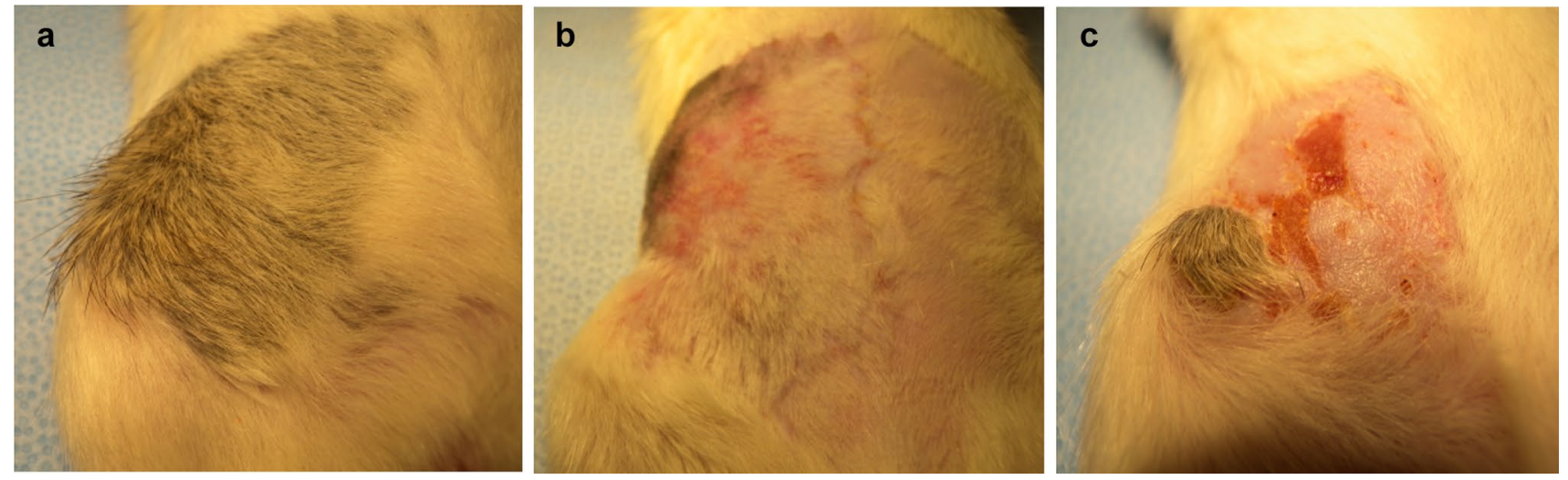

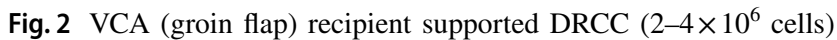
therapy and 7-day immunosuppression protocol of anti- $\alpha \beta$ TCR monoclonal antibody and CsA: a healthy VCA at day 21 post-transplant; b early signs of acute rejection at day 105 post-transplant; $\mathbf{c}$ rejection at 115 days post-transplant. The signs of acute rejection included hair loss, edema and epidermolysis (b) which progressed to ulceration, shrinkage and mummification of the graft (c) 


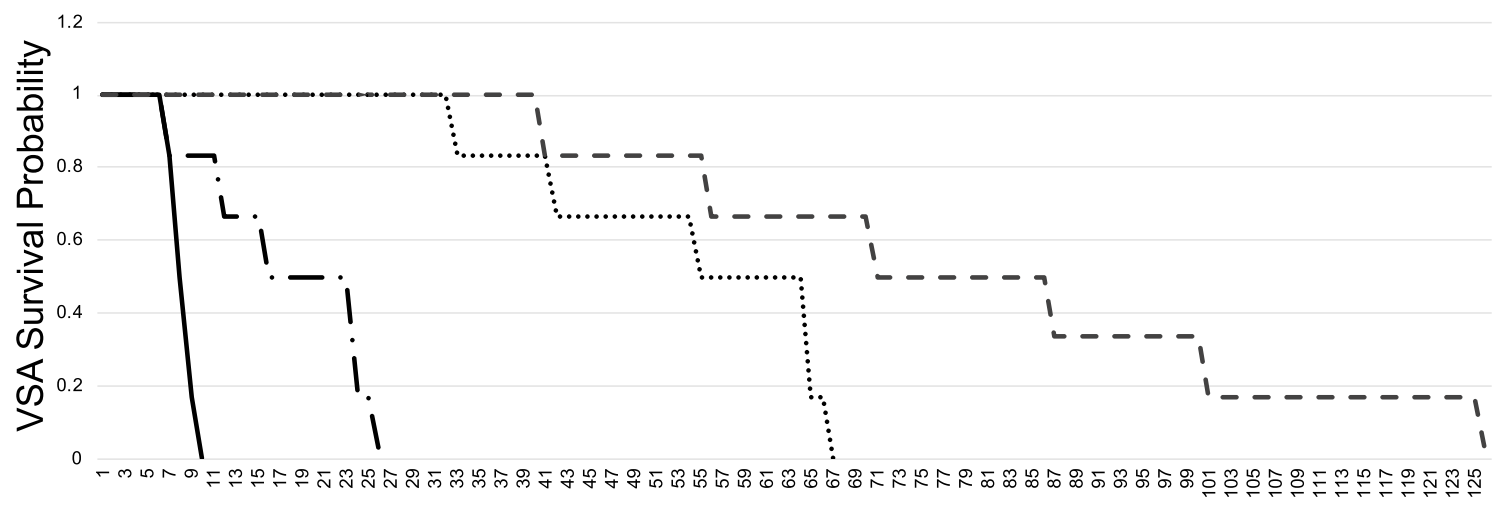

Time Post-transplant (Days)

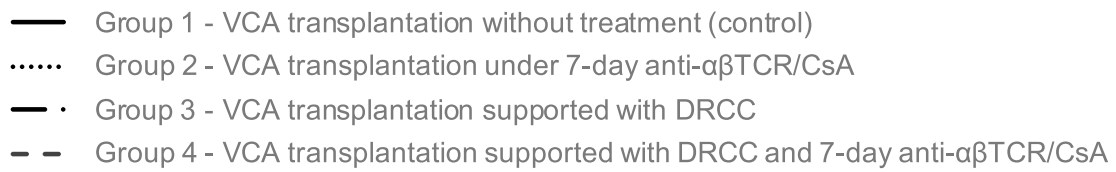

Fig. 3 Kaplan-Meier survival curve of fully MHC-mismatched VCA transplanted from ACI $\left(\mathrm{RT} 1^{\mathrm{a}}\right)$ donors to Lewis $\left(\mathrm{RT} 1^{\mathrm{l}}\right)$ recipients

day $35-35.8 \pm 1.4 \% * * *$ and $39.4 \pm 6.9 \% * * *$, respectively; $* * p<0.01$ vs. Groups 1 and 3; ***p $<0.001$ vs. Group 3 ) compared to Group 1 and 3 (day $7-62.6 \pm 2.1 \%$ and $64 \pm 3 \%$, respectively; Group 3: day $21-60.8 \pm 13.2 \%$, day $35-64.6 \pm 4.7 \%)$. At day $63 \mathrm{PT}$, the CD4 population in Group 2 revealed $38.3 \pm 1.4 \%$, while in Group 4 reached $49.8 \pm 4.2 \% *(* p<0.05$ vs. Group 2$)$ and further increased to $55.9 \pm 4.7 \%$ was detected at day 100 (Fig. $4 \mathrm{~b}$ ).

The depletion of cells expressing $\alpha \beta$-TCR at days 7 and $21 \mathrm{PT}$ followed by recovery starting at day 35 in the IS treated VCA groups mirrored the pattern observed for $\mathrm{CD} 3$ cell population (day 7: Group $1-67.3 \pm 6.7 \%$, Group $2-0.5 \pm 0.3 \% * * *$, Group $3-67.2 \pm 6.5 \%$, Group $4-2.1 \pm 1.8 \% * * * ; * * * p<0.001$ vs. Groups 1 and 3; day $21-$ Group $2-2.1 \pm 1.4 \% * * *$, Group 3-66.9 $\pm 7.7 \%$, Group $4-1.2 \pm 0.7 \% * * *$; $* * * p<0.001$ vs. Group 3; day

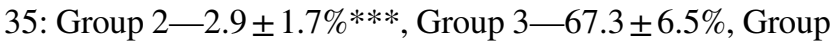
$4-16.6 \pm 6.4 \% * * * ; * * * p<0.001$ vs. Group 3).

The $\alpha \beta$-TCR cell population continued to increase at day 63 PT (Group 2-34.7 $\pm 1.6 \% *$ and Group $4-48.9 \pm 10.9 \%$; $* p<0.05$ vs. Group 4; Fig. 4c) reaching $63.4 \pm 1.5 \%$ in Group 4 at 100 days PT.

There was no significant difference in the average percentage of cells expressing $\gamma \delta$-TCR between the VCA recipient group without treatment (Group 1: $1.06 \pm 0.1 \%$ ) and the VCA recipient group receiving IS protocol (Group 2: $0.92 \pm 0.74 \%$ ), DRCC therapy (Group 3: $1.1 \pm 0.2 \%$ ) or combined IS protocol and DRCC therapy (Group 4: $1.6 \pm 0.5 \%$ ) at day 7 PT (Fig. 4d). At day 21 the average percentage of $\gamma \delta$-TCR cells increased in Groups 2 and 4 to $1.85 \pm 0.85 \%$ and $4.1 \pm 0.9 \%{ }^{\#}$, ** $\left({ }^{\#} p=0.001\right.$ vs. day 7 , $* * p<0.01$ vs. Groups 2 and 3 ), respectively. In comparison,
Group 3 maintained the percentage of $\gamma \delta$-TCR cells at level of $0.98 \pm 0.13 \%$ at day 21 and $0.78 \pm 0.34 \%$ at day 35 . Following increase at day 21, Group 2 also presented maintenance of $\gamma \delta$-TCR cells at level of $1.53 \pm 1.02 \%$ and $1.48 \pm 0.4 \%$ at days 35 and 63 PT. In comparison in Group 4 , the population of $\gamma \delta$-TCR cells peaked at day 35 reaching $3.8 \pm 1.8 \% * *(* * p<0.01$ vs. Groups 2 and 3$)$ which was followed by decrease to $2.8 \pm 0.94 \%$ at day 63 and $1.9 \pm 0.8 \%$ at day $100 \mathrm{PT}$.

The assessment of the percentage of CD4/CD25 T regulatory cells at day $7 \mathrm{PT}$ in Groups 2 and 4 supported by IS was significantly lower compared to Group 1 of untreated or Group 3 of DRCC only treated VCA recipients (Group $1-3.1 \pm 0.5 \%$, Group $2-0.7 \pm 0.6 \% * * *$, Group $3-3.3 \pm 0.6 \%$, and Group $4-1.3 \pm 0.3 \% * * * ; * * * p<0.001$ vs. Groups 1 and 3, Fig. 4e). However, the average percentage of Treg population increased in all groups at day 21 PT (Group 2-0.8 $\pm 0.6 \%$, Group 3-4.1 $\pm 1.6 \% *$, Group $4-2.1 \pm 0.8 \% * ; * p<0.05$ vs. Group 2$)$ and continued at days 35 and 63 PT in Group $2(1.7 \pm 1.2 \%$ at day 35 and $2.9 \pm 0.4 \%$ at day 63$)$ and Group $4(3.2 \pm 1.4 \%$ at day 35 and $3.5 \pm 0.4 \%$ at day 63 ) with exception of Group 3 which showed a decrease to $2.9 \pm 1.2 \%$ at day 35 PT; Fig. $4 \mathrm{f}$. At day $100 \mathrm{PT}$, the population of Treg reached $4.4 \pm 0.7 \%$ in Group 4.

\section{DRCC Therapy Induces Peripheral Blood Chimerism in the VCA Recipients}

During follow-up of the VCA transplants, the evaluation of total chimerism in control Group 1 which received no treatment and Group 2 supported only with anti- $\alpha \beta T C R / C s A$ 

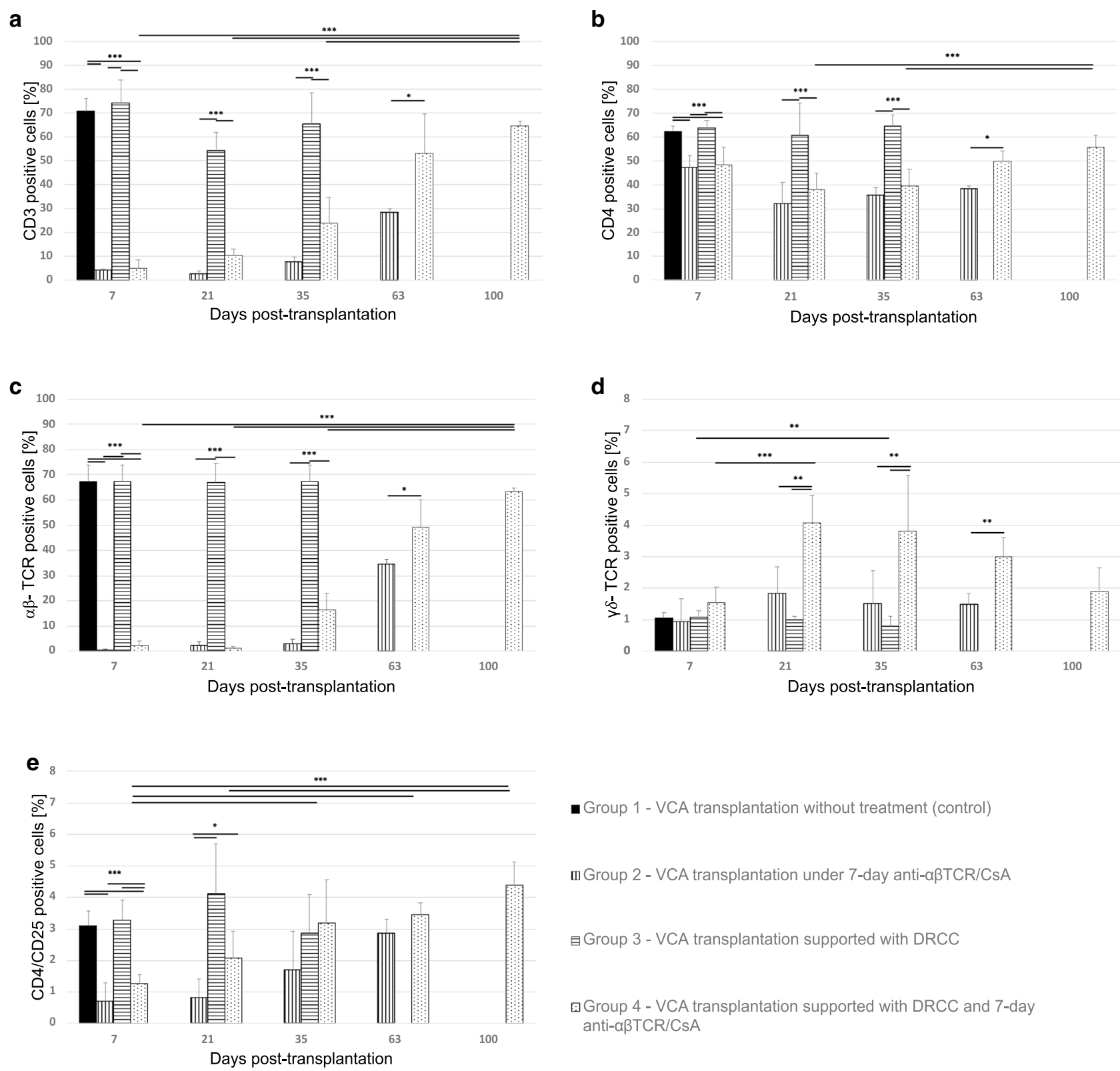

- Group 1 - VCA transplantation without treatment (control)

m Group 2 - VCA transplantation under 7-day anti-aßTCR/CsA

目Group 3 - VCA transplantation supported with DRCC

घGroup 4 - VCA transplantation supported with DRCC and 7-day anti- $\alpha \beta T C R / C s A$

Fig. 4 Comparison of the kinetics of different lymphocyte populations up to 100 days post-VCA transplantation. The levels of: a $\mathrm{CD} 3, \mathbf{b} \mathrm{CD} 4$, $\mathbf{c} \alpha \beta-\mathrm{TCR}, \mathbf{d} \gamma \delta-\mathrm{TCR}$, and e CD4/CD25 lymphocytes were assessed in the peripheral blood of VCA recipients untreated or treated with supportive DRCC therapy and/or 7-day immunosuppression (IS) protocol of anti- $\alpha \beta \mathrm{TCR} / \mathrm{CsA}$. The recipients of fully

MHC-mismatched VCA received the following treatments: Group 1 (black)_VCA recipient without treatment, Group 2 (vertical pattern)-VCA recipient under 7-day IS protocol, Group 3 (horizontal pattern)—VCA recipients supported with DRCC therapy, and Group 4 (dot pattern) - VCA recipients supported with 7-day IS protocol and DRCC therapy. ${ }^{* *} p<0.001, * * p<0.01, * p<0.05$

protocol did not exceed 1.5\% (Group 1: day $7-1.3 \pm 0.2 \%$; Group 2: day $7-1.4 \pm 0.4 \%$, day $21-0.9 \pm 0.5 \%$, day $35-0.83 \pm 0.2 \%$ and day $63-1.35 \pm 0.36 \%$; Fig. $5 a)$. The presence of ACI derived cells was detected in groups that received DRCC therapy. In Group 3 the average chimerism at day 7 was $5.1 \pm 0.85 \%$, at day $21-8.5 \pm 3.8 \%$ and at day $35-5 \pm 2.2 \%$. At day 7 , the total level of chimerism in Group 4 supported with IS and DRCC therapy reached $57.9 \pm 6.2 \% * *$ was significantly higher compared to results in Groups 1, 2, and 3,**p<0.01. Although the number of cells presenting RT $1^{\mathrm{a}}$ in Group 4 decreased during the follow-up period, the total chimerism level was maintained at the level of $\sim 10 \%$ up to 100 days PT (day $21-9.4 \pm 2 \%, p<0.001$ vs. day 7 ; day $35-12 \pm 4.9 \%$; day $63-10.5 \pm 1.4 \% *$ and day $100-10 \pm 1.5 \% ; * p<0.05$ vs. Group 2; Fig. 5a). 

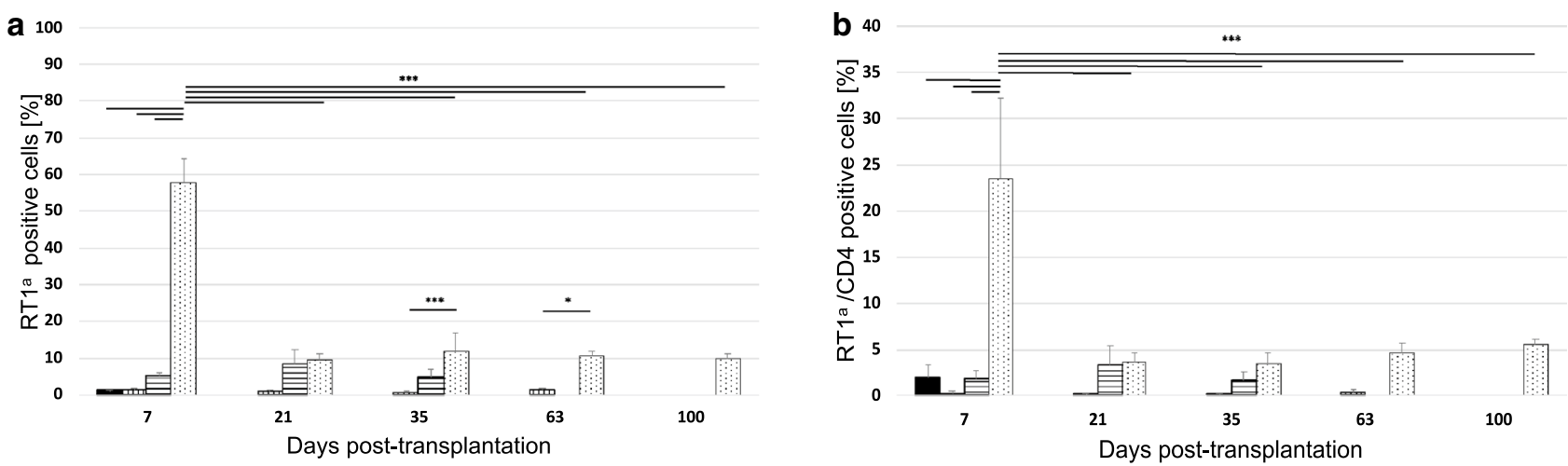

\footnotetext{
- Group 1 - VCA transplantation without treatment (control)

m Group 2 - VCA transplantation under 7-day anti- $\alpha \beta T C R / C s A$

-Group 3 - VCA transplantation supported with DRCC

. Group 4 - VCA transplantation supported with DRCC and 7-day anti- $\alpha \beta T C R / C s A$
}

Fig. 5 Comparison of the kinetics of (a) the total chimerism (RT1 $\left.{ }^{\mathrm{a}}\right)$ and (b) chimerism within the $\mathrm{CD} 4$ cell population (RT1\% $1 \mathrm{CD} 4)$ detected in peripheral blood of the VCA recipients with or without the supportive therapy with DRCC and/or 7-day immunosuppressive protocol of anti- $\alpha \beta \mathrm{TCR} / \mathrm{CsA}$. The recipients of fully MHC-mismatched VCA received the following treatments: Group 1 (black) -

The chimerism of CD4 cell population (RT1\% $1 \mathrm{CD} 4)$ mirrored the pattern observed during the total chimerism analysis. At day 7 PT RT1 $\%$ CD4 chimerism level in Group 1 was at the level of $2 \pm 1.2 \%$, in Group $2-0.3 \pm 0.2 \%$, and in Group 3-1.9 $\pm 0.9 \%$; Fig. 5b) were significantly lower compared to $\mathrm{RT} 1 \mathrm{a} / \mathrm{CD} 4$ chimerism detected in Group 4 $(23.5 \pm 8.7 \% * * * ; * * * p<0.001$ vs. Groups 1,2 , and 3$)$. At day 21 , the $\mathrm{RT} 1$ a $/ \mathrm{CD} 4$ chimerism in Group 4 significantly decreased to $3.6 \pm 1 \% * * *(* * * p<0.001$ vs. day 7$)$ and was maintained at similar level at the following time points: $3.5 \pm 1.2 \%$ at day $35,4.7 \pm 1 \% * * *$ at day 63 and $5.5 \pm 0.6 \% *$ at day $100 \mathrm{PT}(* * * p<0.001$ vs. Group $2, * p<0.05$ vs. Group 2).

\section{Confirmation of Migratory Properties of DRCC In Vivo}

The confocal microscopy and PCR analysis of peripheral blood, BM from the injected femur, thymus, spleen, and lymph node samples harvested at the endpoint in Groups 2, 3 , and 4 assessed the presence of double labeled PKH26/ PKH67 DRCC to determined the migratory properties of DRCC in vivo. No cells were detected in blood and BM samples of VCA recipients supported only with IS protocol (Group 2). The DRCC were found in the peripheral blood and BM of one of VCA recipients supported with DRCC therapy (Group 3) and two VCA recipients supported with IS protocol in combination with DRCC (Group 4); Fig. 6.

Similarly, the analysis of the lymphoid organs using fluorescent microscopy indicated the presence of DRCC
VCA recipient without treatment, Group 2 (vertical pattern) - VCA recipient under 7-day IS protocol, Group 3 (horizontal pattern)VCA recipients supported with DRCC therapy, and Group 4 (check pattern)-VCA recipients supported with 7-day IS protocol and DRCC therapy. $* * * p<0.001, * p<0.05$

in thymus and spleen of two VCA recipients in Group 4 (Fig. 6). In addition, the DRCC were also observed in the spleen of one VCA recipient in Group 3, however, no cells were present in the thymus. No cells were detected in thymus and spleen of VCA recipients in the control Group 2 as well as in the samples of lymph nodes in any of the experimental groups.

The findings of PCR analysis detecting the presence of MHC class I sequences specific for ACI $\left(\mathrm{RT}^{\mathrm{a}}{ }^{\mathrm{a}}\right)$ donors in the VCA recipients supported the results of flow cytometry detecting peripheral blood chimerism and microscopy detecting the long-term mainenance of DRCC in vivo (Fig. 7).

\section{Discussion}

The concept of autologous and allogeneic cell-based therapies has been gaining momentum in recent years in almost all branches of medicine. In the field of transplantation, the encouraging results of experimental and clinical BMT studies (Cowan et al. 2012; Deng et al. 2004; Foster et al. 1998; Garcia-Morales et al. 1998; Leventhal et al. 2012; Siemionow et al. 2002b, 2008) propelled interest in development of novel targeted cell therapies for tolerance induction (Hivelin et al. 2016; Hutchinson et al. 2008; Kaufman et al. 1994; Scandling et al. 2018; Singh et al. 2018).

We introduced a novel DRCC which we have created in vivo (Hivelin et al. 2016) and ex vivo via PEG-mediated cell fusion (Cwykiel et al. 2021). The proposed approach 

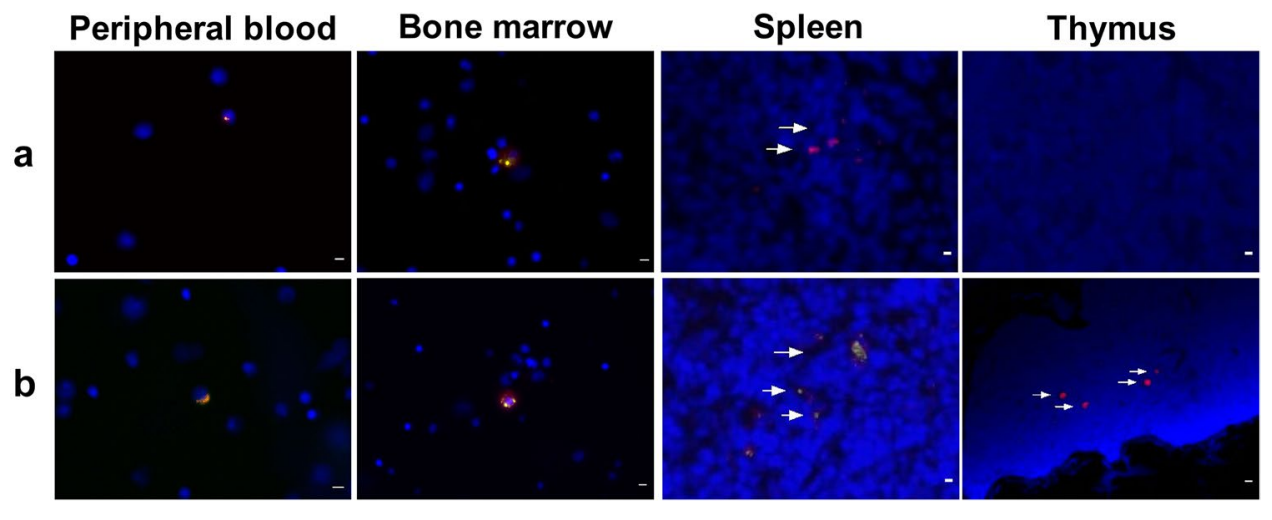

Fig. 6 Representative fluorescence images confiming the long-term engraftment of DRCC transplanted as a supportive therapy to the recipients of VCA without immunosupression (day 25 post-transplant, (a) or receipients receiving combined DRCC and 7-day protocol of anti- $\alpha \beta T C R / C s A$ (day 100 post-transplant, (b). Double labeled PKH26/PKH67 DRCC were observed in the peripheral blood, BM harvested from the injected femoral bone, thymus and spleen of two
VCA recipients at days which received suppotive therapy of DRCC and 7-day immunosupressive protocol of anti- $\alpha \beta \mathrm{TCR} / \mathrm{CsA}$ (Group 4), while in Group 3 where VCA recipients received only DRCC therapy, the double labeled PKH26/PKH67 DRCC were detected in the peripheral blood, BM, and spleen of one VCA recipient. For merge: Red: PKH26; Green: PKH67; Blue: DAPI (nuclei); Magnification $\times 20$, scale bars $10 \mu \mathrm{m}$

\section{Peripheral blood}

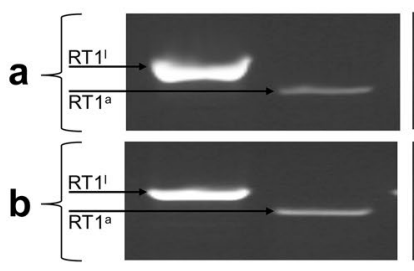

Bone marrow

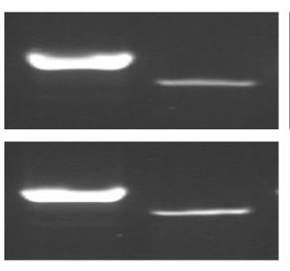

Spleen

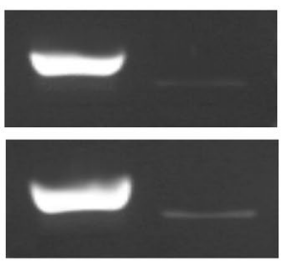

Thymus

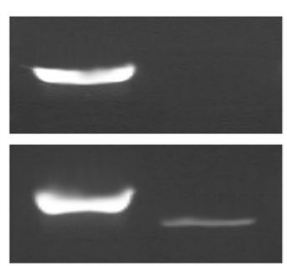

Fig. 7 Representative polymerase chain reaction (PCR) results confirming the presence of donor-derived cells in the VCA (groin flap) recipients receiving DRCC without immunosuppression (Group 3, A) or VCA recipients receiving DRCC combined with the 7-day IS protocol of anti- $\alpha \beta-T C R / C s A$ (Group 4, B). Samples of peripheral blood, BM, spleen, and thymus of VCA recipients from Groups 2,

aimed to create cell therapy supporting tolerance induction in solid organ and VCA recipients offering mixed donor and recipient phenotype, decreased immunogenicity and improved engraftment and chimerism development without myeloablative conditioning of transplant recipient. In our previous in vitro study (Cwykiel et al. 2021), we established the protocol to create DRCC ex vivo and confirmed the decreased immunogenicity of DRCC as well as protolerogenic profile of cultured DRCC presented by secretion of IL-10 and TGF $\beta 1$. Moreover, DRCC demonstrated proliferation and differentiation capabilities comparable to BMC controls.

These promising results encouraged us to assess immunomodulatory properties of DRCC in vivo as a supportive therapy for VCA recipients. DRCC testing was performed in a rat groin flap transplantation model (Demir et al. 2005). The DRCC were delivered using our well-established protocol of intraosseous injection (Klimczak et al. 2007). We have
3 , and 4 collected at the endpoint of experiments (VCA rejection) were analyzed using PCR detecting MHC class I sequences specific for ACI (RT1a; $388 \mathrm{bp}$ ) and Lewis (RT11; $448 \mathrm{bp}$ ) rats. The analysis confirmed the presence of donor-derived cells in the peripheral blood, $\mathrm{BM}$, and spleen of VCA recipients in Group 3 and peripheral blood, $\mathrm{BM}$, spleen, and thymus of VCA recipients in Group 4

previously confirmed that intraosseous route of cell delivery improves engraftment of injected cells by reduction of cell sequestration from the blood stream, and, therefore, is more effective for long-term chimerism induction compared to the intravenous injection (Klimczak et al. 2007; Siemionow et al. 2005b). In addition, intraosseous cells delivery is safer compared to intravenous route since it prevents cells from lodging in the lungs. Recent reports on intraosseous delivery of cord-blood cells and mesenchymal stem cell in the clinical trials confirm our findings of better cell engraftment and safety of the procedure (Bonifazi et al. 2019; Döring et al. 2020; Frassoni et al. 2008; Goto et al. 2018; Lee et al. 2013; Marktel et al. 2019). The DRCC therapy was tested with and without a 7-day non-myeloablative IS protocol of anti$\alpha \beta T C R / C s A$. The rationale for selection and duration of the IS protocol was based on our previous studies assessing the 7-day IS protocol in rat limb, face and groin flap VCA models (Demir et al. 2005; Hivelin et al. 2016; Ozer et al. 2004; 
Siemionow and Klimczak 2013; Siemionow et al. 2002b, 2003), which confirmed its efficacy in extending VCA survival and supporting chimerism induction.

In this study, application of DRCC therapy significantly extended VCA survival compared to the untreated controls, specifically when supported with 7-day IS protocol where the longest allograft survival (125 days) was observed. In contrast, the longest survival of VCA under IS protocol (Group 2) reached 67 days which was in line with previously published groin flap survival data under the same IS protocol (Demir et al. 2005). We also observed a significant extension of allograft survival in the study testing in vivo created DRCC under the same IS protocol in a face allotransplantation model (Hivelin et al. 2016) which also confirms the immunomodulatory effect and pro-tolerogenic properties of DRCC therapy. Interestingly, in vascularized BMT model $100 \%$ allograft survival was achieved up to 100 days PT under 7-day anti- $\alpha \beta$ TCR/CsA IS protocol (Siemionow et al. 2008) and transplantation of VCA combined with vascularized bone component significantly extended allograft survival (125 days) compared to 50\% reduction of survival in VCA transplant without bone component despite application of the same IS protocol (Ozmen et al. 2006a). The higher survival rates observed in the VCA models containing vascularized bone component validate previous reports on the immunomodulatory role of BMCs supporting development of donor-derived chimerism and tolerance in VCA transplants (Siemionow and Klimczak 2013; Siemionow et al. 2003, 2008).

We hypothesize that application of DRCC therapy in VCA models containing vascularized bone component may accelerate development of a stable long-term macrochimerism. The synergistic effect of regulatory cell populations which are present within the $\mathrm{BMC}$ and tolerogenic properties of DRCC will lead to improved VCA survival and tolerance induction in the transplant recipients.

As confirmed by clinical transplant studies, VCA transplants, such as hand or arm, do not contain sufficient amount of red marrow to promote HSC engraftment and establish long-term chimerism (Szajerka et al. 2011). Thus, from the clinical perspective, transplanting vascularized bone in the context of VCA as a tolerance inducing strategy is challenging. Intraosseous delivery of higher dose or multiple dosages of DRCC therapy provides similar or even superior support of VCA transplants without the need for immunosuppression and additional surgical procedure.

Our IS protocol used in this study confirmed previously reported (Ozer et al. 2004; Siemionow et al. 2003) significant depletion of the CD3 and $\alpha \beta$-TCR expressing lymphocyte populations at early post-transplant period and start of the recovery of depleted cells around day 21 PT. The comparison between groups with and without application of anti- $\alpha \beta T C R / C s A$ IS protocol, confirmed selective depletion and preservation of the $\gamma \delta \mathrm{T}$ cell population (Siemionow and Klimczak 2009) which is known to fight infection, development of tumors and have modulates activity of the effector cells involved in local immune response in tissues, such as skin (Fujihashi et al. 1999; Locke et al. 2006; Nanno et al. 2007).

The application of 7-day IS protocol resulted in significant $>40 \%$ decrease of the CD4 population at day 21 post-transplant in groups supported with DRCC therapy when compared to the untreated controls. It has been shown in vitro and in vivo that CsA halts development of CD4 expressing cells and interferes with CD4 mediated responses (Fischer et al. 1991). Analogously, application of $\alpha \beta-T C R /$ CsA protocol significantly reduced the number of Tregs in VCA recipients compared to the control groups without IS. However, the application of DRCC therapy resulted in more efficient recovery of Treg cell population leading to "rescue" and higher numbers of Tregs over time, which was not observed in VCA recipients receiving IS without DRCC supportive therapy. Replacing the CsA with either tacrolimus or rapamycin in the IS protocol could improve the efficacy of the DRCC therapy by increasing the Treg population, thus supporting development of tolerogenic effect via peripheral tolerance mechanism (Stallone et al. 2016).

We have observed maintenance of the long-term macrochimerism in the peripheral blood of VCA recipients supported with DRCC therapy, whereas microchimerism was observed in VCA treated with IS protocol only which correlated with significantly reduced allograft survival.

Our study confirmed that DRCC are capable to engraft with or without application of a short-term IS protocol; however, under the 7-day IS, the total chimerism levels were 10-times higher in VCA recipients receiving combined IS and DRCC therapy compared to the recipients receiving only IS protocol. Moreover, this significantly higher chimerism level was maintained over the entire follow-up period only in the combined DRCC and IS therapy group, whereas gradual chimerism decline was observed under other treatment protocols. These results are comparable with chimerism levels observed in VCA transplants supported with BMT (Klimczak et al. 2007).

In addition, chimerism kinetics for $\mathrm{CD} 4$ cell population (RT1\% $\%$ CD4 were maintained at 5\% level up to the experimental endpoint only in VCA recipients treated with combined DRCC and IS protocol, which is in line with previously published study testing 7 -day $\alpha \beta$-TCR/CsA protocol in VCA models (Demir et al. 2005; Siemionow et al. 2005b).

We have confirmed that the presence of vascularized bone component of the VCA transplant provides a constant source of the donor-derived cells leading to the development of stable chimerism induction at high levels (20-25\%) up to 100 days post-transplant in the MHC-mismatched limb transplants supported with 7-day $\alpha \beta$-TCR/CsA which was 
associated with tolerance induction and allograft survival over 350 days post-transplant (Siemionow et al. 2003). However, in the clinical scenario transplantation of VCA including substantial bone component to induce tolerance is technically demanding and not always possible thus, different experimental models of VBMT were proposed as an alternative methods for tolerance induction (Gordon et al. 2007; Klimczak et al. 2006; Siemionow et al. 2008). Our study assessing development of chimerism in VBMT model under 7 day anti- $\alpha \beta T C R / C s A$ showed a gradual chimerism decline reaching $1 \%$ at 100 days PT which was associated with the gradual development of fibrosis within the donor's bone (Klimczak et al. 2006; Siemionow and Klimczak 2013). Thus, intraosseous delivery of cell therapy to the BM niche as performed in the current study may overcome this hurdle since it will lead to more effective engraftment of cells allowing for maintenance of the long-term chimerism.

We have also confirmed by confocal and fluorescent microscopy and PCR, long-term maintenance of chimerism which correlated with the presence of DRCC in the BM compartment, as well as thymus and spleen at the study endpoint confirming migratory capabilities of DRCC. These findings may provide foundation for the possible mechanism of action of DRCC in vivo, showing immunomodulatory effects, thus altering the $\mathrm{T}$ cell repertoire by presenting mixed antigens on DRCC surface and/or acting as cells stimulating the regulatory cells via cytokine signaling. Studies in solid organs, VCA and BMT reported migration of donor-derived cells to the recipient's lymphoid tissues and organs as well as lungs, skin and liver and confirmed their role in tolerance induction process (Khan et al. 1996; Ozmen et al. 2006b; Siemionow et al. 2006; Zor et al. 2020). Both thymus and spleen are considered as immune cell rich organs participating in innate and adaptive immune response (Dor et al. 2003; Gagliani et al. 2013). Studies testing effect of thymectomy on transplantation tolerance confirmed the significance of thymus in tolerance induction mechanisms (Vagefi et al. 2004) and correlation of the BMC engraftment and thymic chimerism with central tolerance induction (Horner et al. 2006). Spleen, the secondary lymphoid organ, has been also associated with immunomodulation contributing to alloantigen tolerance induction by harboring the myeloid derived suppressor cells (Wang et al. 2013) and MSC (Krampera et al. 2007; Sakata et al. 2018), as well as creating permissive environment to induce regulatory cells, such as Treg (Getts et al. 2011; Masli et al. 2002). These studies confirming immunomodulatory role of thymus and spleen support our findings of long-term chimerism maintenance which correlated with the presence of DRCC in spleen and thymus confirmed by immunofluorescence imaging.

The groin flap VCA model containing highly immunogenic skin component was selected to challenge the in vitro confirmed immunomodulatory properties of DRCC therapy.
Although we did not achieve tolerance, our study was in line with previous reports confirming that total chimerism level below $20 \%$ was associated with acute rejection of the allograft (Dubernard et al. 2007; Foster et al. 1998; Petruzzo et al. 2003; Siemionow and Klimczak 2013; Siemionow et al. 2005a); However, our study highlighted the role of DRCC in establishing long-term chimerism where the possible mechanism of action of DRCC would be based on the recipient's immunomodulation via central (confirmed the presence of DRCC in the thymus) or peripheral tolerance (confirmed the presence of DRCC in the spleen). The limitations of this study include the lack of assessment of the direct and indirect interactions between DRCC and VCA recipient's immune cells in vivo; however, it provides basis for future in vivo exploration of the mechanism of DRCC action focusing on their involvement in the immunoregulatory processes to increase the efficacy of DRCC for the potential therapeutic application in the clinical scenario of solid organs, VCA, and BM transplantation.

Since the clinical BM transplantation and living donor solid organ transplantation, such as kidney or liver, are elective procedures due to donor availability, the DRCC therapy can be prepared in advance and delivered at the day of transplantation. In clinical cases of VCA transplantation access to the large volume of the donor BM will allow to create sufficient number of cells via multiple cell fusions which will be sufficient for the first peri-transplant dose of DRCC. Propagation of DRCC after transplant will allow for delivery of additional doses based on the assessment of donor chimerism. Moreover, DRCC can be cryopreserved after culture and administrated at long-term follow-up to support VCA survival in case of signs of chronic graft rejection. Thus, DRCC represent novel therapeutic approach for the maintenance of chimerism and extension of VCA survival.

\section{Conclusions}

This proof of concept study confirmed in vivo the immunomodulatory potential of DRCC therapy and its role in induction and maintenance of long-term chimerism which correlated with significant extension of VCA survival when combined with short 7-day $\alpha \beta$-TCR/CsA IS protocol. Thus, DRCC represents a novel promising approach for clinically feasible customized donor-recipient cell-based therapy with immunomodulatory properties supporting development of chimerism in solid organs and VCA transplants.

Acknowledgements The authors thank Jacek Szopinski, MD, PhD, Bahar Bassiri Gharb, MD, PhD, Antonio Rampazzo, MD, Grzegorz Brzezicki $\mathrm{MD}, \mathrm{PhD}$ as well as Cleveland Clinic flow cytometry and imaging cores for technical support in the study. 
Funding This work was supported by funding from Department of Defense Armed Force Institute of Regenerative Medicine (AFIRM, W81XWH-08-2-0034).

Availability of data and material All data generated in this study are included in the manuscript and are available for presentation upon request.

\section{Declarations}

Conflict of interest The authors have no financial conflict of interest.

Ethics approval This study was approved by Cleveland Clinic's Institutional Animal Care and Use Committee (IACUC \#2012-0841, Cleveland, Ohio) which is accredited by the American Association for the Accreditation of Laboratory Animal Care (AAALAC).

Open Access This article is licensed under a Creative Commons Attribution 4.0 International License, which permits use, sharing, adaptation, distribution and reproduction in any medium or format, as long as you give appropriate credit to the original author(s) and the source, provide a link to the Creative Commons licence, and indicate if changes were made. The images or other third party material in this article are included in the article's Creative Commons licence, unless indicated otherwise in a credit line to the material. If material is not included in the article's Creative Commons licence and your intended use is not permitted by statutory regulation or exceeds the permitted use, you will need to obtain permission directly from the copyright holder. To view a copy of this licence, visit http://creativecommons.org/licenses/by/4.0/.

\section{References}

(2011) Guide for the care and use of laboratory animal resources (8th edition). National Academies Press, Washington, D.C.

Ahmed KA, Munegowda MA, Xie Y et al (2008) Intercellular trogocytosis plays an important role in modulation of immune responses. Cell Mol Immunol 5:261-269. https://doi.org/10.1038/cmi.2008. 32

Alvarez-Dolado M, Pardal R, Garcia-Verdugo JM et al (2003) Fusion of bone-marrow-derived cells with Purkinje neurons, cardiomyocytes and hepatocytes. Nature 425:968-973. https://doi.org/10. 1038/nature02069nature02069

Bonifazi F, Elisa Dan E, Labopin M et al (2019) Intrabone transplant provides full stemness of cord blood stem cells with fast hematopoietic recovery and low GVHD rate: results from a prospective study. Bone Marrow Transplant 54:717-725. https://doi.org/10. 1038/s41409-018-0335-x

Camargo FD, Finegold M, Goodell MA (2004) Hematopoietic myelomonocytic cells are the major source of hepatocyte fusion partners. J Clin Invest 113:1266-1270. https://doi.org/10.1172/JCI21 301

Cowan ML, Sciammas R, Chong AS (2012) Experimental models of B cell tolerance in transplantation. Semin Immunol 24:77-85. https://doi.org/10.1016/j.smim.2011.08.018

Cwykiel J, Madajka-Niemeyer M, Siemionow M (2021) Development of donor recipient chimeric cells of bone marrow origin as a novel approach for tolerance induction in transplantation. Stem Cells Invest 8:8. https://doi.org/10.21037/sci-2020-044

Demir Y, Ozmen S, Klimczak A et al (2005) Strategies to develop chimerism in vascularized skin allografts across MHC barrier. Microsurgery 25:415-422. https://doi.org/10.1002/micr.20140
Deng W, Han Q, Liao L et al (2004) Allogeneic bone marrow-derived flk-1+Sca-1- mesenchymal stem cells leads to stable mixed chimerism and donor-specific tolerance. Exp Hematol 32:861-867. https://doi.org/10.1016/j.exphem.2004.06.009

Dittmar T, Zanker KS (2015) Tissue regeneration in the chronically inflamed tumor environment: implications for cell fusion driven tumor progression and therapy resistant tumor hybrid cells. Int J Mol Sci 16:30362-30381. https://doi.org/10.3390/ijms161226240

Dor FJ, Gollackner B, Cooper DK (2003) Can spleen transplantation induce tolerance? A review of the literature. Transpl Int 16:451460. https://doi.org/10.1007/s00147-003-0640-0

Döring M, Kluba T, Stanchi KMC et al (2020) Longtime outcome after intraosseous application of autologous mesenchymal stromal cells in pediatric patients and young adults with avascular necrosis after steroid or chemotherapy. Stem Cells Dev 29:811822. https://doi.org/10.1089/scd.2020.0019

Dubernard JM, Lengelé B, Morelon E et al (2007) Outcomes 18 months after the first human partial face transplantation. N Engl J Med 357:2451-2460. https://doi.org/10.1056/NEJMoa072828

Fischer AC, Laulis MK, Horwitz L et al (1991) Effect of cyclosporine on T lymphocyte development. Relationship to syngeneic graft-versus-host disease Transplantation 51:252-259. https://doi.org/10.1097/00007890-199101000-00042

Foster RD, Fan L, Neipp M et al (1998) Donor-specific tolerance induction in composite tissue allografts. Am J Surg 176:418-421

Frassoni F, Gualandi F, Podestà M et al (2008) Direct intrabone transplant of unrelated cord-blood cells in acute leukaemia: a phase I/ II study. Lancet Oncol 9:831-839. https://doi.org/10.1016/S14702045(08)70180-3

Fujihashi K, Dohi T, Kweon MN et al (1999) gammadelta T cells regulate mucosally induced tolerance in a dose-dependent fashion. Int Immunol 11:1907-1916. https://doi.org/10.1093/intimm/11. 12.1907

Gagliani N, Jofra T, Valle A et al (2013) Transplant tolerance to pancreatic islets is initiated in the graft and sustained in the spleen. Am J Transplant 13:1963-1975. https://doi.org/10.1111/ajt.12333

Garcia-Morales R, Carreno M, Mathew J et al (1998) Continuing observations on the regulatory effects of donor-specific bone marrow cell infusions and chimerism in kidney transplant recipients. Transplantation 65:956-965. https://doi.org/10.1097/00007890199804150-00016

Getts DR, Turley DM, Smith CE et al (2011) Tolerance induced by apoptotic antigen-coupled leukocytes is induced by PD-L1+ and IL-10-producing splenic macrophages and maintained by $\mathrm{T}$ regulatory cells. J Immunol 187:2405-2417. https://doi.org/10.4049/ jimmunol.1004175

Gordon CR, Tai CY, Suzuki H et al (2007) Review of vascularized bone marrow transplantation: current status and future clinical applications. Microsurgery 27:348-353. https://doi.org/10.1002/ micr.20367

Goto T, Murata M, Terakura S et al (2018) Phase I study of cord blood transplantation with intrabone marrow injection of mesenchymal stem cells: a clinical study protocol. Medicine 97:e0449. https:// doi.org/10.1097/MD.0000000000010449

Hivelin M, Klimczak A, Cwykiel J et al (2016) Immunomodulatory effects of different cellular therapies of bone marrow origin on chimerism induction and maintenance across MHC barriers in a face allotransplantation model. Arch Immunol Ther Exp 64:299 310. https://doi.org/10.1007/s00005-015-0380-8

Horner BM, Cina RA, Wikiel KJ et al (2006) Predictors of organ allograft tolerance following hematopoietic cell transplantation. Am J Transplant 6:2894-2902. https://doi.org/10.1111/j.1600-6143. 2006.01563.x

Hutchinson JA, Riquelme P, Brem-Exner BG et al (2008) Transplant acceptance-inducing cells as an immune-conditioning therapy in 
renal transplantation. Transpl Int 21:728-741. https://doi.org/10. 1111/j.1432-2277.2008.00680.x

Johansson CB, Youssef S, Koleckar K et al (2008) Extensive fusion of haematopoietic cells with Purkinje neurons in response to chronic inflammation. Nat Cell Biol 10:575-583. https://doi.org/10.1038/ ncb 1720

Kaufman CL, Colson YL, Wren SM et al (1994) Phenotypic characterization of a novel bone marrow-derived cell that facilitates engraftment of allogeneic bone marrow stem cells. Blood 84:2436-2446

Khan A, Tomita Y, Sykes M (1996) Thymic dependence of loss of tolerance in mixed allogeneic bone marrow chimeras after depletion of donor antigen. Peripheral mechanisms do not contribute to maintenance of tolerance. Transplantation 62:380-387. https:// doi.org/10.1097/00007890-199608150-00014

Klimczak A, Agaoglu G, Carnevale KA et al (2006) Applications of bilateral vascularized femoral bone marrow transplantation for chimerism induction across the major histocompatibility (MHC) barrier: part II. Ann Plast Surg 57:422-430. https://doi.org/10. 1097/01.sap.0000227049.65952.26

Klimczak A, Unal S, Jankowska A et al (2007) Donor-origin cell engraftment after intraosseous or intravenous bone marrow transplantation in a rat model. Bone Marrow Transplant 40:373-380. https://doi.org/10.1038/sj.bmt.1705743

Krampera M, Sartoris S, Liotta F et al (2007) Immune regulation by mesenchymal stem cells derived from adult spleen and thymus. Stem Cells Dev 16:797-810. https://doi.org/10.1089/scd.2007. 0024

LaBarge MA, Blau HM (2002) Biological progression from adult bone marrow to mononucleate muscle stem cell to multinucleate muscle fiber in response to injury. Cell 111:589-601. https://doi.org/ 10.1016/S0092-8674(02)01078-4

Lee H, Park JB, Lee S et al (2013) Intra-osseous injection of donor mesenchymal stem cell (MSC) into the bone marrow in living donor kidney transplantation; a pilot study. J Transl Med 11:96. https://doi.org/10.1186/1479-5876-11-96

Lei YM, Sepulveda M, Chen L et al (2019) Skin-restricted commensal colonization accelerates skin graft rejection. JCI Insight 5:e127569. https://doi.org/10.1172/jci.insight.127569

Leventhal JR, Ildstad ST (2018) Tolerance induction in HLA disparate living donor kidney transplantation by facilitating cell-enriched donor stem cell infusion: The importance of durable chimerism. Hum Immunol 79:272-276. https://doi.org/10.1016/j.humimm. 2018.01.007

Leventhal J, Abecassis M, Miller J et al (2012) Chimerism and tolerance without GVHD or engraftment syndrome in HLA-mismatched combined kidney and hematopoietic stem cell transplantation. Sci Transl Med. https://doi.org/10.1126/scitranslmed. 3003509

Lluis F, Cosma MP (2010) Cell-fusion-mediated somatic-cell reprogramming: a mechanism for tissue regeneration. J Cell Physiol 223:6-13. https://doi.org/10.1002/jcp.22003

Locke NR, Stankovic S, Funda DP et al (2006) TCR gamma delta intraepithelial lymphocytes are required for self-tolerance. J Immunol 176:6553-6559. https://doi.org/10.4049/jimmunol. 176.11.6553

Marktel S, Scaramuzza S, Cicalese MP et al (2019) Intrabone hematopoietic stem cell gene therapy for adult and pediatric patients affected by transfusion-dependent B-thalassemia. Nat Med 25:234-241. https://doi.org/10.1038/s41591-018-0301-6

Masli S, Turpie B, Hecker KH et al (2002) Expression of thrombospondin in TGFbeta-treated APCs and its relevance to their immune deviation-promoting properties. J Immunol 168:2264-2273. https://doi.org/10.4049/jimmunol.168.5.2264

Mathes DW, Chang J, Hwang B et al (2014) Simultaneous transplantation of hematopoietic stem cells and a vascularized composite allograft leads to tolerance. Transplantation 98:131-138. https:// doi.org/10.1097/TP.0000000000000204

Nanno M, Shiohara T, Yamamoto H et al (2007) Gammadelta T cells: firefighters or fire boosters in the front lines of inflammatory responses. Immunol Rev 215:103-113. https://doi.org/10.1111/j. 1600-065X.2006.00474.X

Nygren JM, Jovinge S, Breitbach M et al (2004) Bone marrow-derived hematopoietic cells generate cardiomyocytes at a low frequency through cell fusion, but not transdifferentiation. Nat Med 10:494501. https://doi.org/10.1038/nm1040

Ozer K, Izycki D, Zielinski M et al (2004) Development of donorspecific chimerism and tolerance in composite tissue allografts under alphabeta-T-cell receptor monoclonal antibody and cyclosporine a treatment protocols. Microsurgery 24:248-254. https:// doi.org/10.1002/micr.20034

Ozmen S, Ulusal BG, Ulusal AE et al (2006a) Composite vascularized skin/bone transplantation models for bone marrow-based tolerance studies. Ann Plast Surg 56:295-300. https://doi.org/ 10.1097/01.sap.0000199154.85697.13

Ozmen S, Ulusal BG, Ulusal AE et al (2006b) Trafficking of donorderived bone marrow correlates with chimerism and extension of composite allograft survival across MHC barrier. Transplant Proc 38:1625-1633. https://doi.org/10.1016/j.transproceed. 2006.02.154

Petruzzo P, Revillard JP, Kanitakis J et al (2003) First human double hand transplantation: efficacy of a conventional immunosuppressive protocol. Clin Transplant 17:455-460. https://doi.org/ 10.1034/j.1399-0012.2003.00005.x

Powell AE, Anderson EC, Davies PS et al (2011) Fusion between intestinal epithelial cells and macrophages in a cancer context results in nuclear reprogramming. Cancer Res 71:1497-1505. https://doi.org/10.1158/0008-5472.CAN-10-3223

Rizvi AZ, Swain JR, Davies PS et al (2006) Bone marrow-derived cells fuse with normal and transformed intestinal stem cells. Proc Natl Acad Sci USA 103:6321-6325. https://doi.org/10. 1073/pnas.0508593103

Sakata N, Yoshimatsu G, Kodama S (2018) The spleen as an optimal site for islet transplantation and a source of mesenchymal stem cells. Int J Mol Sci 19:1391. https://doi.org/10.3390/ijms1 9051391

Sanges D, Romo N, Simonte G et al (2013) Wnt/beta-catenin signaling triggers neuron reprogramming and regeneration in the mouse retina. Cell Rep 4:271-286. https://doi.org/10.1016/j. celrep.2013.06.015

Scandling JD, Busque S, Dejbakhsh-Jones S et al (2008) Tolerance and chimerism after renal and hematopoietic-cell transplantation. N Engl J Med 358:362-368. https://doi.org/10.1056/ NEJMoa074191

Scandling JD, Busque S, Lowsky S et al (2018) Macrochimerism and clinical transplant tolerance. Hum Immunol 79:266-271. https:// doi.org/10.1016/j.humimm.2018.01.002

Siemionow M, Klimczak A (2009) Immunodepletive anti-alpha/betaTCR antibody in transplantation of composite tissue allografts: Cleveland Clinic research experience. Immunotherapy 1:585-598. https://doi.org/10.2217/imt.09.34

Siemionow M, Klimczak A (2013) Chimerism-based experimental models for tolerance induction in vascularized composite allografts: Cleveland clinic research experience. Clin Dev Immunol 2013:831410. https://doi.org/10.1155/2013/831410

Siemionow M, Oke R, Ozer K et al (2002a) Induction of donor-specific tolerance in rat hind-limb allografts under antilymphocyte serum and cyclosporine A protocol. J Hand Surg 27:1095-1103. https:// doi.org/10.1053/jhsu.2002.36524

Siemionow M, Ortak T, Izycki D et al (2002b) Induction of tolerance in composite-tissue allografts. Transplantation 74:1211-1217. https://doi.org/10.1097/01.TP.0000039850.74639.D0 
Siemionow MZ, Izycki DM, Zielinski M (2003) Donor-specific tolerance in fully major histocompatibility major histocompatibility complex-mismatched limb allograft transplants under an antialphabeta T-cell receptor monoclonal antibody and cyclosporine A protocol. Transplantation 76:1662-1668. https://doi.org/10. 1097/01.TP.0000105343.49626.6F

Siemionow M, Zielinski M, Ozmen S et al (2005a) Intraosseus transplantation of donor-derived hematopoietic stem and progenitor cells induces donor-specific chimerism and extends composite tissue allograft survival. Transplant Proc 37:2303-2308. https:// doi.org/10.1016/j.transproceed.2005.03.127

Siemionow MZ, Klimczak A, Unal S (2005b) Different routes of donor-derived hematopoietic stem cell transplantation for donorspecific chimerism induction across MHC barrier. Transplant Proc 37:62-64. https://doi.org/10.1016/j.transproceed.2004.12.216

Siemionow M, Izycki D, Ozer K et al (2006) Role of thymus in operational tolerance induction in limb allograft transplant model. Transplantation 81:1568-1576. https://doi.org/10.1097/01.tp. 0000209508.37345.82

Siemionow M, Klimczak A, Unal S et al (2008) Hematopoietic stem cell engraftment and seeding permits multi-lymphoid chimerism in vascularized bone marrow transplants. Am J Transplant 8:1163-1176. https://doi.org/10.1111/j.1600-6143.2008.02241.x

Siemionow M, Madajka M, Cwykiel J (2012) Application of cell-based therapies in facial transplantation. Ann Plastic Surg 69:575-579. https://doi.org/10.1097/SAP.0b013e31824803a5

Siemionow M, Rampazzo A, Gharb BB et al (2016) The reversed paradigm of chimerism induction: donor conditioning with recipientderived bone marrow cells as a novel approach for tolerance induction in vascularized composite allotransplantation. Microsurgery 36:676-683. https://doi.org/10.1002/micr.30041

Siemionow M, Cwykiel J, Heydemann A et al (2018a) Dystrophin expressing chimeric (DEC) human cells provide a potential therapy for Duchenne muscular dystrophy. Stem Cell Rev Rep 14:370-384. https://doi.org/10.1007/s12015-018-9807-z

Siemionow M, Cwykiel J, Heydemann A et al (2018b) Creation of dystrophin expressing chimeric cells of myoblast origin as a novel stem cell based therapy for duchenne muscular dystrophy. Stem Cell Rev Rep 14:189-199. https://doi.org/10.1007/ s12015-017-9792-7

Singh AK, Chan JL, Seavey CN et al (2018) CD4+CD25(Hi) FoxP3+ regulatory $\mathrm{T}$ cells in long-term cardiac xenotransplantation. Xenotransplantation 25:e12379. https://doi.org/10.1111/xen. 12379
Stallone G, Infante B, Di Lorenzo A et al (2016) mTOR inhibitors effects on regulatory T cells and on dendritic cells. J Transl Med 14:152. https://doi.org/10.1186/s12967-016-0916-7

Szajerka T, Klimczak A, Jablecki J (2011) Chimerism in hand transplantation. Ann Transplant 16:83-89

Vagefi PA, Ierino FL, Gianello PR et al (2004) Role of the thymus in transplantation tolerance in miniature Swine: IV. The thymus is required during the induction phase, but not the maintenance phase, of renal allograft tolerance. Transplantation 77:979-985. https://doi.org/10.1097/01.tp.0000116416.10799.c6

Vassilopoulos G, Wang PR, Russell DW (2003) Transplanted bone marrow regenerates liver by cell fusion. Nature 422:901-904. https://doi.org/10.1038/nature01539

Wang X, Willenbring H, Akkari Y et al (2003) Cell fusion is the principal source of bone-marrow-derived hepatocytes. Nature 422:897-901. https://doi.org/10.1038/nature01531

Wang D, Yu Y, Haarberg K et al (2013) Dynamic change and impact of myeloid-derived suppressor cells in allogeneic bone marrow transplantation in mice. Biol Blood Marrow Transplant 19:692-702. https://doi.org/10.1016/j.bbmt.2013.01.008

Weimann JM, Johansson CB, Trejo A et al (2003) Stable reprogrammed heterokaryons form spontaneously in Purkinje neurons after bone marrow transplant. Nat Cell Biol 5:959-966. https:// doi.org/10.1038/ncb1053

Willenbring H, Bailey AS, Foster M et al (2004) Myelomonocytic cells are sufficient for therapeutic cell fusion in liver. Nat Med 10:744-748. https://doi.org/10.1038/nm1062

Zhang CC, Lodish HF (2005) Murine hematopoietic stem cells change their surface phenotype during ex vivo expansion. Blood 105:4314-4320. https://doi.org/10.1182/blood-2004-11-4418

Zito F, Lampiasi N, Kireev I et al (2016) United we stand: adhesion and molecular mechanisms driving cell fusion across species. Eur J Cell Biol 95:552-562. https://doi.org/10.1016/j.ejcb.2016.09.002

Zor F, Bozkurt M, Cwykiel J et al (2020) The effect of thymus transplantation on donor-specific chimerism in the rat model of composite osseomusculocutaneous sternum, ribs, thymus, pectoralis muscles, and skin allotransplantation. Microsurgery 40:576-584. https://doi.org/10.1002/micr.30555

Publisher's Note Springer Nature remains neutral with regard to jurisdictional claims in published maps and institutional affiliations. 